\title{
Detection of mycobacteria in aquarium fish in Slovenia by culture and molecular methods
}

\author{
M. Pate ${ }^{1}$, V. Jenčič ${ }^{1}$, M. Žolnir-Dovč ${ }^{2}$, M. Ocepek ${ }^{1, *}$ \\ ${ }^{1}$ Veterinary Faculty Ljubljana, University of Ljubljana, Gerbičeva 60, 1115 Ljubljana, Slovenia \\ ${ }^{2}$ University Clinic of Respiratory and Allergic Diseases, Golnik 34, 4202 Golnik, Slovenia
}

\begin{abstract}
Thirty-five aquarium fish were investigated for the presence of mycobacteria by culture and molecular methods. The following species were examined: goldfish Carassius auratus auratus, guppy Poecilia reticulata, 4 three-spot gourami Trichogaster trichopterus, dwarf gourami Colisa lalia, Siamese fighting fish Betta splendens, freshwater angelfish Pterophyllum scalare, African cichlid fish Cichlidae spp., cichlid fish Microgeophagus altispinosus, cichlid fish Pseudotropheus lombardoi, blue streak hap Labidochromis caeruleus, sterlet Acipenser ruthenus, southern platyfish Xiphophorus maculatus, and catfish Corydoras spp. Isolates of mycobacteria were obtained in 29 cases (82.9\%). Two specimens were positive using Ziehl-Neelsen (ZN) staining, but the cultivation failed. Four specimens were both ZN- and culture-negative. On the basis of GenoType Mycobacterium assay (Hain Lifescience) and restriction enzyme analysis of the amplified products (PCR-RFLP), 23 isolates (79.3\%) were identified: 7 as Mycobacterium fortuitum, 6 as M. gordonae, 6 as M. marinum, 3 as M. chelonae, and 1 as M. peregrinum. Five isolates remained unidentified (Mycobacterium spp.). One case probably represented a mixed infection (M. marinum/M. fortuitum). Since $M$. marinum infections are also detected in humans, the significance of mycobacteria in aquarium fish should not be overlooked.
\end{abstract}

KEY WORDS: Mycobacteria · Aquarium fish $\cdot$ PCR $\cdot$ Restriction enzyme analysis

\section{INTRODUCTION}

Mycobacterial infections are one of the most common infections of aquarium fish. Since their initial discovery at the end of 19th century (Bataillon et al. 1897), fish mycobacterial diseases have been reported to occur worldwide in more than 150 species (Vogel 1958, Nigrelli \& Vogel 1963). The mycobacteria that are generally accepted as fish pathogens are Mycobacterium marinum, $M$. fortuitum and $M$. chelonae. Several other species are listed in the literature but most isolates belong to one of these species (Austin \& Austin 1989).

The disease, usually referred to as fish tuberculosis or mycobacteriosis, has a chronic progressive character. Clinical signs are variable, depending on the main sites of the infection and its severity. Infected fish may appear normal and infection may not be suspected until fish colouration fades and movements become sluggish. Clinical signs also include open lesions and ulcerations, skin inflammation, exophthalmia, and signs of emaciation. Tubercles may occur in all internal organs, but are usually seen on the liver, kidney and spleen (Dulin 1979, van Duijn 1981).

In addition to fish tuberculosis, mycobacteria are capable of causing both localized and disseminated infections in man (Engbaek et al. 1980, Collins et al. 1985, Huminer et al. 1986, Edelstein 1994, Jernigan \& Farr 2000, Enzensberger et al. 2002, Lewis et al. 2003). The risk population involves workers in the seafood industry, people whose hobbies involve water activities and fish enthusiasts. Mycobacterium fortuitum and $M$. chelonae usually cause superficial lesions via skin wounds, but pulmonary disease and cervical lymph node infection may also occur. Most $M$. marinum infections are cutaneous, with the hands being commonly affected (Lucas 1989). The proportion of aquariumrelated $M$. marinum infections in humans reported by Jernigan \& Farr (2000) was $49.2 \%$. Due to the zoonotic 
character of the disease, any suspicion of fish mycobacteriosis should be taken seriously and investigation of the case conducted.

The diagnosis of mycobacterial disease in fish is based on histopathological, culture and molecular methods. The aim of the present study was to identify the species of mycobacteria isolated from aquarium fish in Slovenia in the period from 2001 to 2004 and to compare the available identification methods in order to assess their suitability for routine use.

\section{MATERIALS AND METHODS}

Materials. The internal organs of 35 aquarium fish were investigated. The number of fish and the species investigated were: 11 goldfish Carassius auratus auratus, 7 freshwater angelfish Pterophyllum scalare, 4 three-spot gourami Trichogaster trichopterus, 3 guppy Poecilia reticulata, 2 southern platyfish Xiphophorus maculatus, 1 dwarf gourami Colisa lalia, 1 Siamese fighting fish Betta splendens, 1 African cichlid fish Cichlidae spp., 1 cichlid fish Microgeophagus altispinosus, 1 cichlid fish Pseudotropheus lombardoi, 1 blue streak hap Labidochromis caeruleus, 1 sterlet Acipenser ruthenus, and 1 catfish Corydoras spp.

Bacteriology. Smears made directly from fish organs were stained with Ziehl-Neelsen (ZN). Following homogenization, decontamination with N-acetyl-L-cysteine-sodium hydroxide (NALC-NaOH), and concentration of the specimens, their sediments were inoculated on the following media: Stonebrink, Middlebrook 7H10, Löwenstein-Jensen with pyruvate, LöwensteinJensen with glycerine and Mycobacteria Growth Incubator Tube (MGIT; Becton Dickinson) (Kent \& Kubica 1985). The slants were incubated at $37^{\circ} \mathrm{C}, 30^{\circ} \mathrm{C}$, and at room temperature for 2 mo. The isolates were subjected to physical and biochemical examination in order to identify the species of mycobacteria. The rate of growth at different temperatures, colony morphology and pigmentation were evaluated. Biochemical methods included growth on MacConkey agar, tolerance to $5 \% \mathrm{NaCl}_{\text {, }}$ and the following enzymatic activities: nitrate reductase, semiquantitative catalase at $37^{\circ} \mathrm{C}$, heat-stable catalase at $68^{\circ} \mathrm{C}$, Tween 80 hydrolysis, potassium tellurite reductase, arylsulfatase, pyrazinamidase and urease.

GenoType Mycobacterium assay. GenoType $\mathrm{Myco}$ bacterium (GTM) molecular genetic assay (Hain Lifescience) was also used for identification of mycobacterial species from cultured material. The test is based on the DNA STRIP ${ }^{\circledR}$ technology and permits the identification of 13 mycobacterial species. The procedure is divided into 3 steps: (1) DNA isolation from cultured material, (2) amplification with biotinylated primers, and (3) reverse hybridization. The hybridization includes chemical denaturation of the amplification product, hybridization of the single-stranded, biotinlabelled amplicons to membrane-bound probes, stringent washing, addition of a streptavidin/alkaline phosphatase (AP) conjugate, and an AP-mediated staining reaction. The assay was performed according to the manufacturer's instructions.

AccuProbe Mycobacterium gordonae assay. The AccuProbe Mycobacterium gordonae culture identification test (Gen-Probe) uses a single-stranded DNA probe with a chemiluminescent label that is complementary to the rRNA of the target organism. The labelled DNA probe and the target organism's rRNA combine to form a stable DNA:RNA hybrid. The selection reagent allows the differentiation between nonhybridized and hybridized probe. The labelled DNA:RNA hybrids are measured in a luminometer.

Restriction enzyme analysis of PCR products (PCRRFLP). DNA was extracted using a simplified isolation procedure as follows: a loop full of bacterial culture was suspended in $50 \mu$ l PCR-grade water (Invitrogen), heated for $15 \mathrm{~min}$ at $100^{\circ} \mathrm{C}$ and then centrifuged for $2 \mathrm{~min}$ at $14000 \times \mathrm{g}$. One $\mu \mathrm{l}$ of the supernatant was used for PCR.

A set of previously described genus-specific oligonucleotide primers was used to amplify a $924 \mathrm{bp}$ fragment from the 16S rRNA gene of Mycobacterium spp. Additional internal primers were used to amplify a 300 bp DNA fragment (Talaat et al. 1997). PCR amplification was performed in a GeneAmp PCR system 2400 (Applied Biosystems). PCR products were analysed by electrophoresis on a $2 \%$ agarose gel and visualized by ethidium bromide staining.

Furthermore, PCR products of both amplifications (with external and internal primers) were purified using a Wizard SV Gel and PCR Clean-Up System (Promega). DNA concentration of the amplicons was measured with a biophotometer (Eppendorf). PCR products were then digested with restriction enzymes BanI and ApaI (Promega) according to the manufacturer's recommendations. Digested DNA was analysed by electrophoresis on a $2 \%$ agarose gel and visualized by ethidium bromide staining. The results of restriction enzyme analysis, which discriminates between $\mathrm{Myco-}$ bacterium marinum, $M$. fortuitum and $M$. chelonae were interpreted as described by Talaat et al. (1997).

\section{RESULTS}

\section{Bacteriology}

Among 35 ZN-stained specimens, 13 (37.1\%) gave positive microscopic results for mycobacteria. Using the 
culture method, 29 (82.9\%) mycobacterial isolates were obtained as shown in Table 1. Two specimens were ZN-positive but culturing failed because the material was highly contaminated. Four specimens were both $\mathrm{ZN}$ - and culture-negative. Identification of the species on the basis of physical and biochemical examination was successfully accomplished for 19 (65.5\%) isolates: 7 were identified as Mycobacterium fortuitum, 6 as $M$. marinum, 4 as $M$. gordonae, and 2 as $M$. chelonae. However, only 6 isolates completely matched the published data of distinctive biochemical properties of mycobacteria encountered in clinical specimens described by Metchock et al. (1998). All other isolates were identified on the basis of best-fit analysis (Table 1).

\section{GenoType Mycobacterium assay}

On the basis of the GTM assay performed on 28 isolates, $23(82.1 \%)$ isolates were identified: 7 as Мyco- bacterium fortuitum, 6 as M. gordonae, 6 as M. marinum, 3 as $M$. chelonae, and 1 as $M$. peregrinum. The identification of 5 isolates failed due to non-specific banding patterns on the strips.

\section{PCR-RFLP}

All of the isolates subjected to PCR amplification of 16S rRNA with the first set of primers gave the $924 \mathrm{bp}$ PCR products while the amplification with internal primers yielded $300 \mathrm{bp}$ fragments. Since some of the isolates were previously identified with the GTM assay as species not suitable for investigation with the described restriction enzyme analysis (e.g. Mycobacterium gordonae, $M$. peregrinum), only 20 isolates were investigated using this method. Identification of the species was successfully accomplished in 17 $(85.0 \%)$ cases. Three isolates were identified as $M$. chelonae, 5 as $M$. fortuitum and 9 as $M$. marinum.

Table 1. Mycobacterium spp. Results obtained with 3 methods for the identification of mycobacteria to species level. Mycobacteria were isolated from 29 aquarium fish in the period 2001-2004. ns: not successful; nd: not done; ZN: Ziehl-Neelsen

\begin{tabular}{|c|c|c|c|c|c|c|c|}
\hline \multicolumn{2}{|c|}{ No. Fish species } & \multirow{2}{*}{$\begin{array}{c}\text { Origin } \\
\text { Pet shop }\end{array}$} & \multirow{2}{*}{$\begin{array}{r}\mathrm{ZN} \\
-\end{array}$} & \multirow{2}{*}{$\begin{array}{c}\text { Biochemistry } \\
\mathrm{ns}\end{array}$} & \multirow{2}{*}{$\begin{array}{c}\text { GenoType } \\
\text { Mycobacterium }\end{array}$} & \multirow{2}{*}{$\begin{array}{c}\text { PCR-RFLP } \\
\text { nd }\end{array}$} & \multirow{2}{*}{$\begin{array}{l}\text { Final result } \\
\text { M. gordonae }\end{array}$} \\
\hline 1 & Goldfish Carassius auratus auratus & & & & & & \\
\hline 2 & Goldfish C. auratus auratus & Pet shop & + & M. fortuitum & M. fortuitum & nd & M. fortuitum \\
\hline 3 & Goldfish C. auratus auratus & Pet shop & - & M. fortuitum & M. fortuitum & M. marinum & $\begin{array}{l}\text { M. fortuitum + } \\
\text { M. marinum }\end{array}$ \\
\hline 4 & Three-spot gourami Trichogaster trichopterus & Pet shop & - & ns & M. fortuitum & ns & M. fortuitum \\
\hline 5 & Guppy Poecilia reticulata & Pet shop & - & ns & ns & nd & Mycobacterium spp. \\
\hline 6 & Guppy $P$. reticulata & Pet shop & - & ns & ns & ns & Mycobacterium spp. \\
\hline 7 & Goldfish C. auratus auratus & Pet shop & - & ns & M. gordonae & nd & M. gordonae \\
\hline 8 & Three-spot gourami T. trichopterus & Pet shop & + & M. fortuitum & M. fortuitum & M. fortuitum & M. fortuitum \\
\hline 9 & Guppy $P$. reticulata & Pet shop & + & M. gordonae & M. gordonae & nd & M. gordonae \\
\hline 10 & Cichlid fish Microgeophagus altispinosus & Pet shop & - & M. fortuitum & M. fortuitum & M. fortuitum & M. fortuitum \\
\hline 11 & Cichlid fish Pseudotropheus lombardoi & Private owner & - & ns & M. peregrinum & nd & M. peregrinum \\
\hline 12 & Dwarf gourami Colisa lalia & Private owner & + & M. fortuitum ${ }^{\mathrm{a}}$ & nd & M. fortuitum & M. fortuitum \\
\hline 13 & Goldfish C. auratus auratus & Private owner & - & M. chelonae & M. chelonae & M. chelonae & M. chelonae \\
\hline 14 & Goldfish C. auratus auratus & Private owner & + & ns & ns & nd & Mycobacterium spp. \\
\hline 15 & Goldfish C. auratus auratus & Private owner & - & M. fortuitum ${ }^{\mathrm{a}}$ & M. fortuitum & M. fortuitum & M. fortuitum \\
\hline 16 & Goldfish C. auratus auratus & Private owner & - & ns & ns & ns & Mycobacterium spp. \\
\hline 17 & Sterlet Acipenser ruthenus & Private owner & - & M. fortuitum ${ }^{\mathrm{a}}$ & M. fortuitum & M. fortuitum & M. fortuitum \\
\hline 18 & Goldfish C. auratus auratus & Private owner & + & M. gordonae $e^{\mathrm{a}}$ & M. gordonae & nd & M. gordonae \\
\hline 19 & Goldfish C. auratus auratus & Private owner & - & M. marinum & M. marinum & M. marinum & M. marinum \\
\hline 20 & Goldfish C. auratus auratus & Private owner & + & M. marinum & M. marinum & M. marinum & M. marinum \\
\hline 21 & Freshwater angelfish Pterophyllum scalare & Pet shop & - & M. gordonae $e^{a}$ & M. gordonae & nd & M. gordonae \\
\hline 22 & Freshwater angelfish $P$. scalare & Pet shop & - & $\mathrm{ns}$ & M. chelonae & M. chelonae & M. chelonae \\
\hline 23 & Freshwater angelfish $P$. scalare & Pet shop & - & M. gordonae & M. gordonae & M. marinum ${ }^{\mathrm{b}}$ & M. gordonae \\
\hline 24 & Freshwater angelfish $P$. scalare & Pet shop & - & ns & ns & M. marinum ${ }^{\mathrm{b}}$ & Mycobacterium spp. \\
\hline 25 & Three-spot gourami T. trichopterus & Pet shop & + & M. marinum ${ }^{\mathrm{a}}$ & M. marinum & M. marinum & M. marinum \\
\hline 26 & Three-spot gourami T. trichopterus & Pet shop & + & M. chelonae & M. chelonae & M. chelonae & M. chelonae \\
\hline 27 & Catfish Corydoras spp. & Private owner & + & M. marinum & M. marinum & M. marinum & M. marinum \\
\hline 28 & Southern platyfish Xiphophorus maculatus & Private owner & + & M. marinum & M. marinum & M. marinum & M. marinum \\
\hline 29 & Southern platyfish $X$. maculatus & Private owner & - & M. marinum & M. marinum & M. marinum & M. marinum \\
\hline
\end{tabular}


However, 3 isolates (Nos. 3, 23 and 24, Table 1) identified as $M$. marinum gave different results in other identification tests. Isolate No. 3 was identified as $M$. fortuitum with the GTM assay and with biochemical examination. Based on the colony morphology investigation of the subcultures, it was concluded that the inconsistency of the results was a consequence of mixed infection. Isolate No. 23 was subsequently identified as $M$. gordonae with the GTM assay; the identity was also confirmed with AccuProbe Mycobacterium gordonae assay. Isolate No. 24 had the same restriction enzyme profile as isolates Nos. 3 and 23 but it could not be identified with the GTM assay nor with biochemical examination.

\section{DISCUSSION}

The identification of mycobacteria in tissues is traditionally made by ZN staining. However, acid-fast bacilli (AFB) may not always be found through direct microscopy even though granulomatous lesions are present. Our study revealed positive microscopy results in only $37.1 \%$ cases while Lescenko et al. (2003) reported a higher proportion of ZN-positive results $(58.8 \%)$ in fish parenchymatous organs with granulomas. Low AFB detection (9 to $13.2 \%$, respectively) was reported in Mycobacterium marinum studies in humans (Edelstein 1994, Ang et al. 2000). The reasons for the failure to identify AFB through direct microscopy may include the destruction of mycobacteria or their low number, as well as the possibility of other microorganisms causing granulomas. Streptococcus iniae (Chang \& Plumb 1996, Perera et al. 1998, Shoemaker et al. 2000), fungus Aphanomyces (Hatai et al. 1994, Wada et al. 1994, Roberts \& Rodger 2001) and bacteria of the genus Nocardia (Wolke \& Meade 1974, Chen 1992) have been isolated from the granulomas of cultured and wild fish. Culture examination is a more sensitive method than direct microscopy. Therefore direct microscopic examination should be considered only as an auxiliary diagnostic method. However, it may provide valuable information especially when culture examination fails. Negative cultivation results may be explained by the killing of mycobacteria caused by host defence mechanisms, a low number of viable mycobacteria in the tissue, or by destruction of the mycobacteria during the preparation of the sample (Lescenko et al. 2003).

Biochemical examination is a time consuming method, the results are often difficult to interprete and variations among strains may occur. In many instances it is necessary to identify the organisms based on a best-fit analysis which may result in erroneous identification (Metchock et al. 1998). Additionally, there are usually small differences in biochemical properties among different mycobacterial species which infect fish. Some species with similar physical characteristics may differ in only one or 2 tests (e.g. Mycobacterium fortuitum and M. chelonae or M. marinum and M. gordonae). The reason for the difficult interpretation of the biochemical profile may lie in mixed mycobacterial cultures due to contamination with other bacteria.

Identification of mycobacteria by amplification of a variety of target DNA sequences has been accomplished: 16S rRNA (Rogall et al. 1990, Kox et al. 1995), IS986 (Kolk et al. 1992), IS6110 (Noordhoek et al. 1995), and hsp65 (Plikaytis et al. 1992, Telenti et al. 1993). The possibilities of direct detection and identification of mycobacterial DNA in field samples using molecular methods have been tested with varying success (Talaat et al. 1997, Fiedler et al. 2000). Talaat et al. (1997) described a method that relies on PCR amplification with RFLP of the amplified fragment. This method, discriminating between 3 mycobacterial species, can be applied to either isolated colonies or to infected fish tissues. In the present study, this method was used to identify the isolated colonies. The GenoType Mycobacterium (GTM) assay, allowing the identification of 13 species of mycobacteria, was also performed. A comparison of both methods was performed on 19 isolates. The results of the PCR-RFLP were completely consistent with the results of the GTM assay in 15 cases, including 2 cases when both methods failed to identify the species. The lack of an adequate amount of culture, or mycobacteria other than the species recognizable by PCR-RFLP and GTM assay, are possible reasons for the negative outcome of the testing. In one case (isolate No. 4, Table 1) PCR-RFLP failed but the GTM assay identified the isolate as Mycobacterium fortuitum. In 3 cases the methods gave inconsistent results (Table 1). For the isolate No. 3 it was concluded that the reason might lie in dual infection. Isolates Nos. 23 and 24 were first tested with PCR-RFLP which revealed the $M$. marinum restriction enzyme profile. Subsequently, the GTM assay was performed and isolate No. 23 was identified as M. gordonae while isolate No. 24 could not be identified. Because of identical restriction enzyme profiles of $M$. marinum and $M$. gordonae, the sequence similarity of their 16S rRNA genes was checked. The sequence identity was $97 \%$; the same restriction sites for ApaI and no restriction site for BanI were found in both 16S rRNA resulting in the same length of theoretical restriction enzyme fragments. The sequence comparison was made on $M$. marinum strain DSM 44344 and M. gordonae strain agha3 (GenBank accession numbers AJ536032 and AJ581472, respectively). Restriction enzyme profiles identical to that of $M$. marinum might also be the case for mycobacteria other than $M$. gordonae which may 
lead to false diagnosis. Therefore, this method is probably of little diagnostic value, regardless of the fact that it can be applied directly to infected fish tissues. It enables only the differentiation among a few, albeit the most important species of the mycobacterial species that can infect fish, it is quite time consuming, and most importantly, it may not give reliable results when applied to field samples.

The GTM assay was quite successful; it could be completed within a few hours and allowed the identification of a broad variety of mycobacteria. However, both molecular methods used in the present study may give negative or ambiguous results. To confirm or to further examine unusual results, sequencing of the PCR products or probe-based techniques could be used.

Species of mycobacteria identified in the present study (except Mycobacterium peregrinum) are recognized as aquarium fish pathogens. Lescensko et al. (2003) reported the isolation of M. marinum, M. gordonae, $M$. triviale and $M$. avium subsp. hominissuis from 70 aquarium fish in the Czech Republic. However, the latter 2 species were regarded as accompanying microflora. $M$. fortuitum, $M$. chelonae and $M$. abscessus were reported as causative agents of mycobacterial infections in laboratory-maintained zebrafish Brachydanio rerio (Astrofsky et al. 2000). M. fortuitum has also been isolated from Japanese medaka Oryzias latipes (Sanders \& Swaim 2001). McCormick et al. (1995) reported $M$. chelonae in cichlid oscar Astronotus ocellatus. $M$. fortuitum and $M$. smegmatis were found to be pathogenic for goldfish (Talaat et al. 1999). We have not managed to find any reports describing M. peregrinum infection in fish. Therefore, our results might be the first report of the isolation of $M$. peregrinum from an aquarium fish.

Fish mycobacterioses also pose a risk to the human population. People become infected while working with diseased aquarium fish (Street et al. 1991, Antonio et al. 2000, Lehane \& Rawlin 2000). The consumption of insufficiently heat-treated fish is a presumed source of potentially pathogenic mycobacteria for immunocompromised patients (von Reyn et al. 1996, Ristola et al. 1999). Many case reports of Mycobacterium marinum infections in man exist (Engbaek et al. 1980, Collins et al. 1985, Huminer et al. 1986, Alinovi et al. 1993, Jernigan \& Farr 2000, Casal \& Casal 2001, Enzensberger et al. 2002, Trampuz et al. 2002, Lewis et al. 2003). Jernigan and Farr (2000) reported that $49.2 \%$ of the $M$. marinum infections in humans were aquarium-related and only $2.6 \%$ of infections were due to swimming pool-associated injuries. A retrospective study from 1991 to 1998 of $M$. marinum infections in humans in Spain revealed that 35 out of 39 cases were fish related (Casal \& Casal 2001). A fish-to-human transmission of mycobacteria other than $M$. marinum is also possible. A recent report by Collina et al. (2002) describes $M$. chelonae and $M$. fortuitum infection in 2 people who kept fish.

Mycobacterium marinum infections in humans have been detected in Slovenia. Since 1999, 4 cases were reported by the University Clinic of Respiratory and Allergic Diseases Golnik (M. Žolnir-Dovč unpubl. data). However, M. marinum infections in the human population in Slovenia may be more common, but are not diagnosed since there are usually no investigations of such cases. Hand skin lesions were present in all of the 4 affected patients, 3 of whom had a history as aquarium hobbyists.

This stresses the importance of recognizing fish mycobacterioses in order to prevent their transmission to humans.

\section{CONCLUSIONS}

The lack of AFB in ZN-stained smears does not exclude the possibility of fish mycobacterial infection; a complete investigation including culture and molecular methods is required for a reliable diagnosis. Traditional methods for identification of mycobacteria are well established and relatively inexpensive, but are slow in providing clinically relevant information and are limited in scope to the species for which a large number of strains have been studied. The best diagnostic option to identify the species of mycobacteria from cultured material is the GenoType Mycobacterium assay since it enables fast detection of a variety of mycobacterial species. Since we have detected Mycobacterium marinum in the investigated fish and since Slovenia experiences $M$. marinum infections in humans every year, the importance of mycobacterial infections in aquarium fish should not be overlooked in veterinary or in human medicine.

Acknowledgements. The work was supported by the Slovenian Ministry of Agriculture, Forestry and Food. The authors are indebted to Milojka Šetina for her excellent technical assistance.

\section{LITERATURE CITED}

Alinovi A, Vecchini F, Bassissi P (1993) Sporotrichoid mycobacterial infection. A case report. Acta Dermato Venereol 73:146-147

Ang P, Rattana-Apiromyakij N, Goh CL (2000) Retrospective study of Mycobacterium marinum skin infections. Int $\mathrm{J}$ Dermatol 39:343-347

Antonio DB, Swanson C, Cech JJ, Mager RC, Doroshov S, Hedrick RP (2000) Prevalence of Mycobacterium in wild and captive delta smelt. Calif Dep Fish Game 86:233-243 
Astrofsky KM, Schrenzel MD, Bullis RA, Smolowitz RM, Fox JG (2000) Diagnosis and management of atypical Mycobacterium spp. infections in established laboratory zebrafish (Brachydanio rerio) facilities. Comp Med 50: $666-672$

Austin B, Austin DA (1989) Methods for the microbiological examination of fish and shellfish. Ellis Horwood, Chichester, p 168-169

Bataillon E, Dubard R, Terre U (1897) Un nouveau type de tuberculose. C R Seances Soc Biol Fil 49:446-449

Casal M, Casal MD (2001) Multicenter study of incidence of Mycobacterium marinum in humans in Spain. Int J Tuberc Lung D 5:197-199

Chang PH, Plumb JA (1996) Histopathology of experimental Streptococcus sp. infection in tilapia, Oreochromis niloticus (L.) and channel catfish, Ictalurus punctatus (Rafinesque). J Fish Dis 19:235-241

Chen SC (1992) Study on the pathogenicity of Nocardia asteroides to the Formosa snakehead, Channa maculata (Lacepide). J Fish Dis 15:47-53

Collina G, Morandi L, Lanzoni A, Reggiani M (2002) Atypical cutaneous mycobacteriosis diagnosed by polymerase chain reaction. Br J Dermatol 147:781-84

Collins CH, Grange JM, Noble WC, Yates MD (1985) Mycobacterium marinum infection in man. J Hyg 94: 135-149

Dulin MP (1979) A review of tuberculosis (mycobacteriosis) in fish. Vet Med Small Anim Clin 74:731-735

Edelstein H (1994) Mycobacterium marinum skin infections. Report of 31 cases and review of the literature. Arch Intern Med 154:1359-1364

Engbaek HC, Thormann J, Vergmann B (1980) Aquariumborne Mycobacterium marinum granulomas. Scand J Infect Dis 12:74-78

Enzensberger R, Hunfeld KP, Elshorst-Schmidt T, Boer A, Brade V (2002) Disseminated cutaneous Mycobacterium marinum infection in a patient with non-Hodgkin's lymphoma. Infection 30:393-395

Fiedler Z, Mazurova J, Novotny L, Dvorak P (2000) Rapid diagnosis of mycobacterial infection in a Carassius auratus by specific DNA detection (in Czech). Veterinarstvi 50: 223-224

Hatai K, Nakamura K, Rha SA, Yuasa K, Wada S (1994) Aphanomyces infection in dwarf gourami (Colisa lalia). Fish Pathol 29:95-99

Huminer D, Pitlik SD, Block C, Kaufman L, Amit S, Rosenfeld JB (1986) Aquarium-borne Mycobacterium marinum skin infection. Report of a case and review of the literature. Arch Dermatol 122:698-703

Jernigan JA, Farr BM (2000) Incubation period and sources of exposure for cutaneous Mycobacterium marinum infection: case report and review of the literature. Clin Infect Dis 31:439-443

Kent PT, Kubica GP (1985) Public health mycobacteriology. A guide for the level III laboratory. US Department of Health and Human Services, Centers for Disease Control, Atlanta, GA

Kolk AHJ, Schuitema ARJ, Kuijper S, van Leeuwen J, Hermans PWM, van Embden JDA, Hartskeerl RA (1992) Detection of Mycobacterium tuberculosis in clinical samples by using polymerase chain reaction and a nonradioactive detection system. J Clin Microbiol 30:2567-2575

Kox LFF, van Leeuwen J, Kuijper S, Jansen HM, Kolk AHJ (1995) PCR assay based on DNA coding for 16S rRNA for detection and identification of mycobacteria in clinical samples. J Clin Microbiol 33:3225-3233

Lehane L, Rawlin GT (2000) Topically acquired bacterial zoonoses from fish: a review. Med J Aust 173:256-259

Lescenko P, Matlova L, Dvorska L, Bartos M, Vavra O, Navratil S, Novotny L, Pavlik I (2003) Mycobacterial infection in aquarium fish. Vet Med Czech 48:71-78

Lewis FMT, Marsh BJ, von Reyn CF (2003) Fish tank exposure and cutaneous infections due to Mycobacterium marinum: Tuberculin skin testing, treatment, and prevention. Clin Infect Dis 37:390-397

Lucas SB (1989) Mycobacteria and the tissues of man. In: Ratledge C, Stanford J, Grange JM (eds) The biology of mycobacteria, Vol 3. Clinical aspects of mycobacterial disease. Academic Press, London, p 153-161

McCormick JI, Hughes MS, McLoughlin MF (1995) Identification of Mycobacterium chelonae in a cichlid oscar, Astronotus ocellatus Cuvier, by direct cycle sequencing of polymerase chain reaction amplified 16S ribosomal RNA gene sequences. J Fish Dis 18:459-461

Metchock BG, Nolte FS, Wallace RJ (1998) Mycobacterium. In: Murray PR (ed) Manual of clinical microbiology, 7th edn. ASM Press, Washington, DC, p 399-437

Nigrelli RF, Vogel H (1963) Spontaneous tuberculosis in fishes and in other cold-blooded vertebrates with special reference to Mycobacterium fortuitum Cruz from fish and human lesions. Zoologica 48:130-143

Noordhoek GT, Kaan JA, Mulder S, Wilke H, Kolk AHJ (1995) Routine application of the polymerase chain reaction for detection of Mycobacterium tuberculosis in clinical samples. J Clin Pathol 48:810-814

Perera RP, Fiske RA, Johnson SK (1998) Histopathology of hybrid tilapias infected with a biotype of Streptococcus iniae. J Aquat Anim Health 10:294-299

Plikaytis BB, Plikaytis BD, Yakrus MA, Butler WR, Woodley CL, Silcox VA, Shinnick TM (1992) Differentiation of slowly growing Mycobacterium species, including Mycobacterium tuberculosis, by gene amplification and restriction fragment length polymorphism analysis. J Clin Microbiol 30:1815-1822

Ristola MA, von Reyn CF, Arbeit RD, Soini H, Lumio J, Ranki A, Buhler S, Waddel R, Tosteson ANA, Falkinham JO, Sox $\mathrm{CH}$ (1999) High rates of disseminated infection due to non-tuberculous mycobacteria among AIDS patients in Finland. J Infect 39:61-67

Roberts RJ, Rodger HD (2001) The pathophysiology and systematic pathology. In: Roberts RJ (ed) Fish pathology, 3rd edn. WB Saunders, London, p 55-132

Rogall T, Wolters J, Florh T, Bottger EC (1990) Towards a phylogeny and definition of species at the molecular level within the genus Mycobacterium. Int J Syst Bacteriol 40: $323-330$

Sanders GE, Swaim LE (2001) Atypical piscine mycobacteriosis in Japanese medaka (Oryzias latipes). Comp Med 51:171-175

Shoemaker CA, Evans JJ, Klesius PH (2000) Density and dose: factor affecting mortality of Streptococcus iniae infected tilapia (Oreochromis niloticus). Aquaculture 188: 229-235

Street ML, Umbert-Millet IJ, Roberts GD, Su WPD (1991) Non-tuberculous mycobacterial infections of the skin. J Am Acad Dermatol 24:208-215

Talaat AM, Reimschuessel R, Trucksis M (1997) Identification of mycobacteria infecting fish to the species level using polymerase chain reaction and restriction enzyme analysis. Vet Microbiol 58:229-237

Talaat AM, Trucksis M, Kane AS, Reimschuessel R (1999) Pathogenicity of Mycobacterium fortuitum and $\mathrm{Myco}-$ bacterium smegmatis to goldfish, Carassius auratus. Vet Microbiol 66:151-164 
Telenti A, Marchesi F, Balz M, Bally F, Bottger EC, Bodmer T (1993) Rapid identification of mycobacteria to the species level by polymerase chain reaction and restriction enzyme analysis. J Clin Microbiol 31:175-178.

Trampuz A, Garzoni C, Fluckiger U, Zimmerli W (2002) Persistent ulcers on the hand of an aquarium owner. Scand J Infect Dis 34:630-632

van Duijn C (1981) Tuberculosis in fish. J Small Anim Pract 22:391-411

Vogel H (1958) Mycobacteria from cold-blooded animals. Am

Editorial responsibility: David Bruno,

Aberdeen, UK
Rev Tuberc 77:823-838

von Reyn CF, Arbeit RD, Tosteson ANA, Ristola MA and 19 others (1996) The international epidemiology of disseminated Mycobacterium avium complex infection in AIDS. AIDS 10:1025-1032

Wada SP, Yuasa K, Rha SA, Nakamura K, Hatai K (1994) Histopathology of Aphanomyces infection in dwarf gourami (Colisa lalia). Fish Pathol 29:229-237

Wolke RE, Meade TL (1974) Nocardiosis in chinook salmon. J Wildl Dis 10:149-154

Submitted: January 4, 2004; Accepted: July 28, 2004

Proofs received from author(s): November 5, 2004 